\title{
Can the Mixed Ownership Really Play a Supervisory Role in China?
}

\author{
Feng KONG \\ School of Economics and Management, \\ North China Electric Power University \\ Baoding, China \\ e-mail: 1021816832@qq.com
}

\author{
Yingjia HAO \\ School of Economics and Management, \\ North China Electric Power University \\ Baoding, China \\ e-mail: 1021816832@qq.com
}

\begin{abstract}
While the mixed ownership reform of state-owned enterprises is deepening, there are still lots of corruption, conspiracy and other actions against the interests of enterprises. This paper studies whether the introduction of private capital investors to achieve the purpose of co variance under difference levels of supervision system. In conclusion, private investor will steal state-owned assets under stateowned holding and the possible increases as the ratio increases.
\end{abstract}

Keywords-ownership reform; shareholding ratio of private capital; supervision

\section{INTRODUCTION}

It is necessary for companies to introduce private companies for reducing unfavorable factors and developing state-owned enterprises. Building an efficient modern enterprise system is an important goal of the mixed ownership reform of state-owned enterprises. The CPC Central Committee and the State Council issued the "Guidance on Deepening the Reform of State-owned Enterprises" in 2015. It is clear that the development of mixed ownership economy is an important way to deepen the reform of state-owned enterprises, and made a very clear deployment.

Foreign views on mixed ownership reform are not the same. Mohammed Omran argues that the privatization of state-owned enterprises has not significantly improved the role of state-owned enterprises, however, having a positive effect on the privatization of enterprises involved-the spillover effect of state-owned enterprises [1]. Pablo Arocena and Diana Oliveros recognize that the efficiency of state-owned enterprises after privatization is significantly improved, and the private enterprises themselves do not have much impact [2]. Laura Cabeza Carcia and Silvia Gomez Anson highlighted the factors that influence the success of privatization, pointing out the comparative results of traditional and external privatization: once the industry effect is taken into account, it can not show a significant improvement in the profitability and operations of the private sector in the medium term, and that the economic environment plays an important role in the success of privatization [3]. Jose E. Farinos, C. Jose Garcia, Ana Ma Ibanez argue that the privatization of state-owned enterprises in Spain has led to the conclusion that privatization has played a positive role in improving the efficiency of state-owned enterprises [4]. Someone suggests that it may be optimal for governments to carry out corporatization of SOEs before eventual privatization [6]. A policy implication of Chen G and Firth M, Rui O's study is that the state needs to relinquish ownership control of listed firms so that economic efficiency and financial performance can be improved [7].

\section{CONCLUSION OF THE UNDERLYING MODEL}

In the state-owned enterprises "mixed reform", the introduction of private capital shares, will form stateowned trustees, private capital investors and state-owned enterprises operators multiparty participation in the game relationship.

In the state-owned enterprises "mixed change", you can have a number of private capital investors, their investment ratio is generally not more than the proportion of stateowned shares. Therefore, the operator's principle-agent contract is generally owned by the state-owned trustees (holding), and the other contributions have a certain supervisory function. However, due to information asymmetry, private capital investors are likely to form a conspiracy with the operators to damage the cost of stateowned assets in exchange for personal interests. However, due to information asymmetry, private capital investors are likely to form a conspiracy with the operators to damage the cost of state-owned assets in exchange for personal interests. In order to facilitate the analysis, assuming that there is only one private investor, set its shareholding ratio of $\lambda$, all the shares will be implemented "one-in-one principle".

\section{A. Operator Behavior Function}

He behavior of the operator can be based on its impact on the performance of the enterprise, and on the basis of the previous literature, this article will be divided into normal hard work and speculation. Norma effects that the operator to take the daily business behavior to improve the performance of enterprises, with "a"; Speculation refers to misconduct by corrupting corporate performance in exchange for corruption in the interests of the operator's own, with " $a_{s}$ ".

The firm's performance is the linear function of the operator's behavior

$$
\pi=a-a_{s}+\theta
$$

Where $\theta$ is an exogenous random various, which obeys 
the normal distribution with mean o and variance.

The operator takes both of these actions to pay the cost. Let the operator's normal effect cost function:

$$
c(a)=\frac{1}{2} b a^{2}
$$

Where $b_{s}$ is the cost factor for the operator to speculate.

In general, the two behaviors of the operator are independent or irrelevant (negligible). Therefore, this paper assumes that the operator's total behavior cost function is:

$$
c\left(a, a_{s}\right)=\frac{1}{2} b a^{2}+\frac{1}{2} b_{s} a_{s}^{2}
$$

Supervision of the behavior of capital investment

Assuming that the supervision of private capital contributors is $\mathrm{P}$, the greater the intensity of supervision, the greater the likelihood that the operator's behavior is found. Therefore, it is possible to define the intensity of supervision as the possibility that the operator's speculation is found.In other words, when the operator takes speculation, the probability of being found is $P$.

The supervision needs to pay the cost of supervision. Let the supervisory cost function be:

$$
c(P)=\frac{1}{2} M P^{2}
$$

Which is set to supervise the cost factor and $M \geq 0$.

If the operator's speculation is found, will be subject to certain penalties. The intensity of punishment and the operator was found in the size of the speculative behavior, set the penalty strength function.

$$
G_{s}=f_{s} a_{s}
$$

Where ${ }^{G_{s}}$ is the rate of punishment for the operator's speculative behavior, that is , the intensity of the penalty.

\section{B. Participate in the Utility Function of the Parties}

1) The utility function of the operator

Assuming the enterprise to the operator's reward incentive contract:

$$
S=\alpha+\beta \pi
$$

Among them, $\alpha$ indicates the fixed wage income of the operator, $\beta$ indicates operators share the proportion of corporate output.

Set the operator's speculative behavior of gray income:

$$
S_{s}=k_{s} a_{s}
$$

Where $k_{s}$ is the utility coefficient of speculative behavior, expressing the difficulty of speculation, smaller speculative coefficient means greater difficulty, $0 \leq k_{s} \leq 1$.

Assuming that the operator takes a rent-seeking behavior to seek a conspiracy between the two parties, if the private capitalist agrees to collusion, he will not exercise the supervision. Set the operator in accordance with the "one share" the proportion of rent-seeking, then the rentseeking cost.

$$
R_{s}=\lambda m S_{s}=\lambda m k_{s} a_{s}
$$

Among them, Rs for the rent-seeking costs, that is, private capitalist bribery to obtain the gray income for the operator rent-seeking strength coefficient.

Assuming that the operator is risk aversion, the utility function of the operator has the same absolute risk aversion. When the private

Capitalists choose conspiracy, the operator's expected utility is $U_{y}$, deterministic equivalent income is:

$$
U_{y}=S+S_{s}-c(a)-\frac{1}{2} \beta^{2} \rho \sigma^{2}-\lambda m S_{s}
$$

Where $\frac{1}{2} \beta^{2} \rho \sigma^{2}$ is the risk cost of the operator, $\rho$ is the operator's risk aversion coefficient, $\rho \geq 0$; and $\rho \sigma^{2}$ can be regarded as the operator's risk cost coefficient.

$$
U_{n}=S+S_{s}-c(a)-\frac{1}{2} \beta^{2} \rho \sigma^{2}-P G_{s}
$$

\section{2) Utility function of private investor}

Fama put forward the conclusion that reputation will produce utility, and the theory of reputation utility is the idea of solving the problem of principle-agent [6]. Private capital investors will also have a reputation for the effectiveness of consideration. If assuming that private capitalists take into account their expected reputation utility, they will choose not to conspiracy with the operators, set the capital contribution to their expected reputation for $\zeta$. Assuming private investors in the choice of conspiracy behavior, their expected reputation for the effectiveness of o, that is, regardless of their credibility.

For private investors, the pursuit of the interests of enterprises is not to maximize, but to maximize their own interests. Therefore, with the operator collusion or not the benefits will affect the number of private capital investors choose to conspiracy. 
Set the choice of conspiracy, the private capitalists expect utility, for ${ }^{\prime}{ }_{y}^{\prime}$ :

$$
U_{y}^{\prime}=\lambda(\pi-S)+\lambda m k_{s} a_{s}
$$

Not set the choice of conspiracy, the expected utility of the private investor is $U_{n}^{\prime}$ :

$$
U_{n}^{\prime}=\lambda(\pi-S)-\frac{1}{2} M P^{2}+\lambda P G_{s}+\zeta
$$

\section{GAME MODEL AND ANALYSIS}

As mentioned earlier, both the operator and the private contributor choose the optimal behavior aimed at maximizing their utility.

\section{A. The Optimal Selection Model of the Operator}

1) When the operator and the private capital of the conspiracy

The operator's optimal behavior selection function is:

$$
\begin{aligned}
& \max U_{y}=S+S_{1}-c(a)-\frac{1}{2} \rho \beta^{2} \sigma^{2}-\lambda m S_{1} \\
& \text { s.t.a, } \mathrm{a}_{\mathrm{s}} \geq 0
\end{aligned}
$$

The optimal level of effort for the operator is:

$$
\begin{aligned}
& a^{*}=\frac{\beta}{b} \\
& a_{s}^{*}=\max \left(\frac{k_{s}-\beta-\lambda m k_{s}}{b_{s}}, 0\right)
\end{aligned}
$$

2) When the operator does not conspire with the private capital

The operator's optimal behavior selection function is:

$$
\begin{aligned}
& \max U_{n}=S+S_{s}-c(a)-\frac{1}{2} \rho \beta^{2} \sigma^{2}-P G_{s} \\
& \text { s.t.a, } \mathrm{a}_{\mathrm{s}} \geq 0
\end{aligned}
$$

Get the best level of effort for the operator:

$$
\begin{aligned}
& a^{*}=\frac{\beta}{b} \\
& a_{s}^{*}=\max \left(\frac{k_{s}-\beta-P f_{s}}{b_{s}}, 0\right)
\end{aligned}
$$

At the time $a_{s}=0$, speculation, rent-seeking behavior, collusion behavior will not happen. By the operator's optimal behavior can be seen to reduce ks, improve fs, bs, $\beta$, $\mathrm{P}$ can reduce or even eliminate the occurrence of speculative behavior.

\section{B. Public-funded Investor's Behavioral Choice Model}

When the operator has speculative behavior, private capital investors will be based on collusion with the operator to bring their own income to decide whether to choose conspiracy.

1) Collusion, the supervision of private investors to choose the intensity of $P=0$, its expected utility is:

$$
U_{y}^{*}=\lambda(1-\beta)\left(\frac{\beta}{b}-\frac{k_{s}-\beta-m k_{s}}{b_{s}}+\theta\right)-\lambda \alpha+\lambda m k_{s} \frac{k_{s}-\beta-m k_{s}}{b_{s}}
$$

2) When the conspiracy, the private capitalists choose the optimal supervision efforts to maximize their utility:

$$
\begin{aligned}
& \max U_{n}=\lambda(\pi-S)-\frac{1}{2} M P_{1}^{2}+\lambda P_{1} G_{s} \\
& \text { s.t. } a^{*}=\frac{\beta}{b} ; a_{s}{ }^{*}=\frac{k_{s}-\beta-P_{1} f_{s}}{b_{s}}
\end{aligned}
$$

The optimal supervision of the capital contribution is:

$$
\begin{gathered}
P^{*}=\frac{\lambda f_{s}\left(1+k_{s}-2 \beta\right)}{2 \lambda f_{s}^{2}+b_{s} M} \\
U_{n}^{*}=\lambda(1-\beta)\left[\frac{\beta}{b}-\frac{k_{s}}{b_{s}}+\frac{\beta}{b_{s}}+\frac{\lambda f_{s}^{2}\left(1+k_{s}-2 \beta\right)}{2 \lambda b_{s} f_{s}^{2}+b_{s}^{2} M}+\theta-\lambda \alpha\right] \\
-\frac{\lambda^{2} f_{s}^{2}\left(b_{s} M+2 \lambda f_{s}^{2}\right)\left(1+k_{s}-2 \beta\right)^{2}}{2 b_{s}\left(2 \lambda f_{s}^{2}+b_{s} M\right)^{2}}+\frac{\lambda^{2} f_{s}^{2}\left(k_{s}-\beta\right)\left(1+k_{s}-2 \beta\right)}{2 \lambda b_{s} f_{s}^{2}+b_{s}^{2} M}
\end{gathered}
$$

\section{Selection Model of Optimal Compensation Contract}

The choice of the optimal compensation contract, that is, the optimal determination by the state-owned funders to determine the target and the "co-change" the same goal, that is, to maximize the performance of enterprises as the goal, and set up private capital to participate in supervision.

$$
\max (\pi-S)
$$

$$
\begin{aligned}
\text { s.t. (IR)U } & =\alpha+\beta \pi-\frac{1}{2} b a^{2}-\frac{1}{2} \rho \beta^{2} \sigma^{2} \geq \bar{w} \\
(I C) a & =\frac{\beta}{b} ; a_{s}=\frac{k_{s}-\beta-P f_{s}}{b_{s}} \\
P & =\frac{\lambda f_{s}\left(1+k_{s}-2 \beta\right)}{2 \lambda f_{s}^{2}+b_{s} M}
\end{aligned}
$$

The incentive coefficient of the optimal compensation contract of the operator is:

$$
\beta^{*}=\frac{1}{\left(1 / b+\rho \sigma^{2}\right)} *\left(\frac{1}{b}+\frac{1}{b s}-\frac{2 \lambda f_{s}^{2}}{2 \lambda b_{s} f_{s}^{2}+b_{s}^{2} M}\right)
$$


Substituting $\beta^{*}$ into (16) and (19) respectively, you can get in the optimal compensation contract, private capital investors choose to collusion with the operator of the maximum utility value.

\section{An Analysis Model of Consent Behavior of Private Investors}

Under the optimal compensation contract, set up a private investor conspiracy behavior selection function $f(\lambda)$ :

$$
f(\lambda)=U_{n}^{*}-U_{y}^{*}
$$

When $f(\lambda)>0$, indicating that the maximum efficiency of non-conspiracy of private capital investors is higher than the conspiracy situation, obviously will make the choice of unconventional behavior; otherwise, when $f(\lambda)<0$, the private capital investors will choose conspiracy behavior.

Substituting the parameters into (21), we can see that it is a complex multiples function. As the other parameters change, there will be a variety of trends in the $[0,0.5]$ range, and multiple fictitious behavior thresholds may occur. Parameters that affect the value include: $f_{s}, b_{s}, m, \rho \sigma^{2}, b, \zeta, k_{s}$ and so on.

\section{SIMULATION OF THE MODEL}

The initial value of the main parameters and their values are shown in the following table. The selection and analysis of the initial values take into account the performance of the enterprises. The value of the various behaviors must be guaranteed to be greater than zero. The proportion of stateowned shares is greater than $50 \%$, that is, the proportion of individual private capital contribution can not reach the proportion of holding, otherwise the model of the optimal contract failure. Under the simulation analysis, the possibility of $\mathrm{M}$ collusion of private capital is analyzed.

TABLE I. Parameter Initial Value Setting and its Value RANGE

\begin{tabular}{cc}
\hline Parameter & $\begin{array}{c}\text { Initial } \\
\text { value }\end{array}$ \\
\hline$k_{s}$ & 0.7 \\
$b_{s}$ & 4.0 \\
$m$ & 0.3 \\
$b$ & 0.3 \\
$f_{s}$ & 2.0 \\
$\zeta$ & 0.002 \\
$\lambda$ & \\
\hline
\end{tabular}
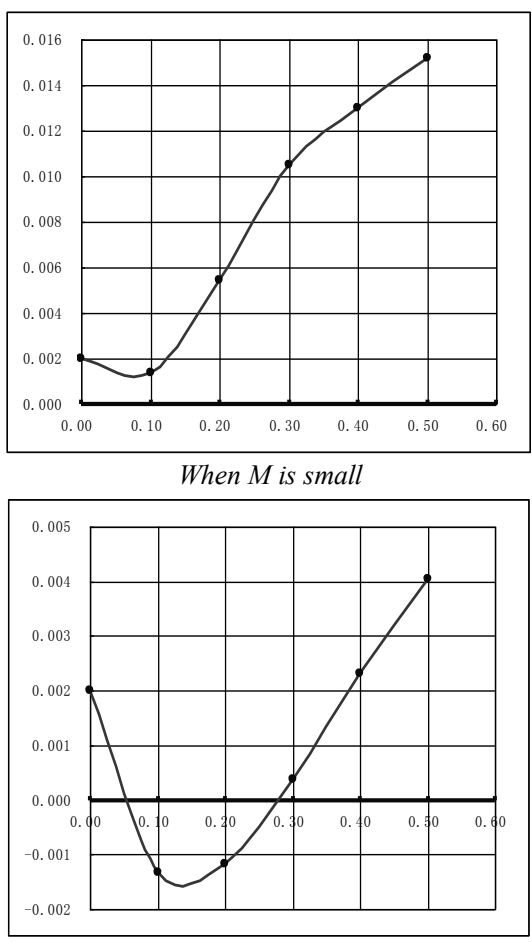

when $M$ is medium

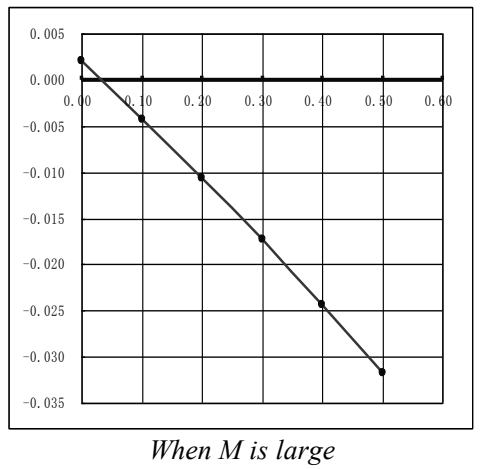

Figure 1. The impact of $\mathrm{M}$ on collusion

\section{CONCLUSION}

According to $f(\lambda)$ change trend can be divided into the parameters of small, medium and large three representative of the situation. In order to visualize the results of the analysis, the graphs are used to give the analysis results. The abscissa in the graph shows that the intersection with the abscissa is the critical value of the conspiracy. In the case of a large supervision coefficient, that is, the supervision system is not perfect, the penalty coefficient is small, the introduction of private capital not only can not play a balance effect, but will induce private capital investors to steal state-owned assets.

China's state-owned enterprises mixed ownership research is a worthy of in-depth study of the problem. It is worth nothing that this paper does not consider the proportion of private ownership than the shareholding ratio of state-owned shares, and more than two investors did not in-depth study of the situation, these are to be made later in- 
depth study problem.

\section{REFERENCES}

[1] Mohammed Omran. The performance of stated-owned enterprises and newly privatized firms: Does privatization really matter? [J].World Development,2004,32 (6): 1019-1041.

[2] Pablo Arocena., Diana Oliveros. The efficiency of stated-owned and privatized firms: Does ownership make a difference?[J].production Economics, 2012, 140: 457-465.

[3] Laura Cabeza Carcia, Silvia Gomez Anson., The Spanish privatization process: Implications on the performance of divested firms. International Review of Financial Analysis,2007, 16: 390-409.
[4] Jose E. Farinos, C. Jose Garcia, Ana Ma Ibanez, Operating and stock market performance of state-owned enterprise privatizations: The Spanish experience $[\mathrm{J}]$, International Review of Financial Analysis, 2007,16:367-389.

[5] E Fama. Agency Problems and the Theory of the Firm [J]. Journal of Political Economy,1980,88 (2): 288-307.

[6] Aivazian V A, Ge Y, Qiu J. Can corporatization improve the performance of state-owned enterprises even without privatization?[J]. Journal of Corporate Finance, 2005, 11 (5): 791808.

[7] Chen G, Firth M, Rui O. Have China's enterprise reforms led to improved efficiency and profitability? [J]. Emerging Markets Review, 2006, 7(1):82-109. 